\title{
Catastrophe of Japanese Psychiatric Brainbank-in Case of Fukushima
}

\section{Keiko lkemoto*}

Department of Psychiatry, Iwaki Kyoritsu General Hospital, Iwaki, 973-8555, Japan

\begin{abstract}
Brain bank is an indispensable research resource for pathophysiological studies of mental illnesses. In Japan, a national law for autopsy and dead body storage has been applied to manage brain bank, though this law is said to need some amendment for research use of human brain materials. In history of Japanese psychiatry, problems of Utsunomiya Hospital, manifested in 1987, caused serious loss of credit on psychiatric research and psychiatric medicine. It was reported that autopsy had been done by no autopsy-qualified individuals for example nurses in Utsunomiya Hospital. Recently, following the Great East Japan Earthquake and nuclear disaster, Fukushima Psychiatric Brain bank, established in 1997, has continued its activity in spite of lacking an autopsy-qualified researcher among them. This illegality has been concealed for approximately 2 years. Some problems which have disturbed development of psychiatric brain bank and post-mortem brain studies of psychiatric illnesses in Japan were discussed.
\end{abstract}

Keywords: Brainbank; Autopsy qualification; Ethico-legal problem; Research resource

\section{Introduction}

Brain research using post-mortem brain tissues has been pivotal to explore pathogenesis of neuropsychiatric diseases. Owing to postmortem brain studies, pathophysiology of neuropsychiatric diseases as well as mystery of human brains has successfully been revealed. For this purpose, brainbanks, i.e. research resources of post-mortem brain tissues, have had an essential role. However, there has not yet been universal ethico-legal consensus and world law to manage brainbanks. Some ethico-legal problems and moral dilemma that rose in some countries have not been easily detected by international medical and/ or scientific societies. It has been said that establishment of Japanese brainbank system has been far delayed in comparison with that in US and European countries. In the present article, the author argues some Japanese problems that disturb psychiatric brain research, and focuses on problems in Fukushima Psychiatric Brainbank [1-3].

\section{Ethico-Legal Problems}

Human tissue and Bio-banking is a complex field and running brain banks needs to abide by several golden standards in order to avoid pitfalls in basic research:1) A donor system in which informed consent is granted for the use of the samples for scientific research, including genetic analysis and access to medical records, 2) Rapid autopsy system, 3) Compatibility of protocols for procurement, management, handling and storage, 4) A generally accepted consensus on diagnostic criteria, 5) Quality [4] control, 6) Abiding by local/international legal and ethical guidelines for work with human material, 7) Proper safety procedures. In Fukushima Psychiatric Brainbank in Japan, registration in advance to death as well as importance of informed consent from family has been emphasized.

In Japan, autopsy and brain storage has been allowed in some limited situations or individuals, which has been indicated by a national law. Under this law that indicates autopsy and human dead body storage, human brain materials have been far accessible for limited officially autopsy-qualified researchers assigned by the Ministry of Health, Welfare and Labor in Japan, or for professors and associate professors of departments of anatomy, legal medicine, and pathology. In Japan, under this law, autopsy qualification can be submitted only by medical doctors or dentist assigned by the Ministry of Health, Welfare and Labor in Japan, whereas some professors or associate professors of anatomical department, who are autopsy-qualified do not have qualification of medical doctor (MD) or dentist. Thus, in Japan, human brain samples have been far accessible for officially autopsy-qualified researchers, the number of which is limited. Further, Japanese research system has not yet allowed legal autopsy brains to be used by researchers other than the field of legal medicine. This has long been another obstacle for researchers in the field other than legal medicine, because control samples in pathophysiological studies are hard to obtain in autopsy other than forensic studies. Needs of some amendment of Japanese law for autopsy and dead body storage has been mentioned in view point to promote brain research and establishing brainbanks.

\section{Problems of Excessively Ambitious Researchers}

In such a situation, legal and/or ethical restriction for research use of human brain samples would readily be ignored by ambitious brain researchers in Japan. In recent international congress, such as the World Federation of Biological Psychiatry (WFSBP) in Kyoto, Japan, in 2013, it was noted that some Japanese researchers managed the Fukushima Psychiatric Brainbank as if they had an autopsy-qualified researcher among them, though they had already expelled the one from their research group following the Great East Japan Earthquake and nuclear disaster. This illegality has been concealed for approximately 2 years. To make the matter worse, a man MD researcher who was a graduate student during the period when the autopsy-qualified woman MD researcher participated in the Fukushima Psychiatric Brainbank, gained the WFSBP congress prize in 2013. Surprisingly, most researchers did not regard this situation as a serious matter, or pretended to be so.

*Corresponding author: Keiko Ikemoto, Department of Psychiatry, Iwaki Kyoritsu General Hospital Iwaki, Fukushima, 973-8555, Japan, Tel: +81-246-267-3151; Fax: +81-246-27-2148; E-mail: ikemoto@iwaki-kyoritsu.iwaki.fukushima.jp

Received December 15, 2014; Accepted March 03, 2015; Published March 09 2015

Citation: Ikemoto K (2015) Catastrophe of Japanese Psychiatric Brainbank-in Case of Fukushima. J Psychiatry 18: 259 doi: 10.4172/1994-8220.1000259

Copyright: (c) 2015 Ikemoto K. This is an open-access article distributed under the terms of the Creative Commons Attribution License, which permits unrestricted use, distribution, and reproduction in any medium, provided the original author and source are credited 


\section{Problems of Women Abuse}

Women researchers rather than men are more likely to fall the victim to academic harassment caused by men's excessive ambition. In Japan, as an Asian country, women's social status is relatively low compared with that in US and European countries. Women abuse that exists commonly in Japanese societies, is usually concealed. Recent increase of female students in university medical faculty has lead to reveal the problems in side of Japanese women MD. In fact, many of Japanese MD researchers are obliged to have their children out of marital relationship, whose fathers are usually their professors of departments, and/or supervisor. Single mothers who rear children without husbands are no rare. In such a situation, ambitious women MD and researchers urge the children's fathers to let the other women MD or researchers expel out from their medical and/or academic field(s). Now, almost all of women professors in psychiatric department in Japanese University have experienced to work as single mothers having more than two children of their supervisors. It should be noticed that such harassment in Japanese style may be a reason why neuropathological or histochemical research using human brain materials has not yet been advanced, and the establishment of Psychiatric Brainbanks has not yet been progressed. In US and European countries, a large contribution of women researchers of neuropathologists and histochemists in brain science has been well-recognized. For example, Dr. Francine M Benes in Harvard Brainbank, Dr. Mayada Akil in the National Institute of Mental Health (NIMH) Brainbank, Dr. Victoria Arango in Columbia
University, New York, Dr. Natalia A Uranova in Russia, Dr. Etienne C Hirsch in Pitié-Salpêtrière Hospital in Paris, and so on.

In this context, it is not only Japanese legal system, but also men's excessive ambition that caused to violate legal restrictions, and academic and sexual harassment of Japanese style, that has long disturbed development of Japanese brainbank and progress of brain research.

\section{Perspective}

The Japanese Society of Psychiatry and Neurology newly established the Gender Equality Promotion Committee, and its first meeting was held on the 14th, September, 2013. It is expected that promotion of gender equality in Japanese academic societies would help to promote brain research in Japan, and also to recover the catastrophic situation of Fukushima Psychiatric Brainbank.

\section{References}

1. Ikemoto K (2008) "Neural stem cells and Epigenetics" as new strategies for psychiatric research using post-mortem brains: After the 1st Symposium for Brain Bank, 22 October 2006, Fukushima, Japan, Comment on "Banking on the future of stem cells" Nature 452: 263.

2. Ravid R, Ikemoto K (2012) Pitfalls and practicalities in collecting and banking human brain tissues for research on psychiatric and neurological disorders. Fukushima J Med Sci 58: 82-87.

3. Ikemoto K (2015) Catastrophe of Japanese psychiatric brainbank. J Psychother Psychol Disor 2:1

4. Ikemoto K (2012) Neuropathological research of mental illnesses: "D-cell hypothesis" of schizophrenia. Jpn J Gen Hosp Psychiatry 24: 388-397. 